\section{Ocular phototherapy}

AD Singh

Introduction

Phototherapy can be translated to mean 'light or radiant energy-induced treatment.' For the purpose of this review, the scope of phototherapy will be limited to photocoagulation, thermotherapy, and photodynamic therapy (PDT) as these three modalities are frequently used to treat a wide variety of ocular tumours.

\section{Sources of light}

Lasers (light amplification by stimulated emission of radiation) have become the exclusive source of light or radiant energy for all applications of phototherapy in treatment of ocular tumours. ${ }^{1,2}$ Inherent properties of laser such as monochromatic wavelength (single or narrow bandwidth), coherent waves, and nondivergence provide high-energy source that can be easily manipulated. ${ }^{3}$ Argon and krypton laser have wavelengths within the visible spectrum (400-700 nm). Nd-Yag laser and $\mathrm{Co}_{2}$ laser emit infrared wavelengths. Excimer laser is in the ultraviolet range. ${ }^{3}$

\section{Tissue interaction}

Depending on the wavelength, intensity, and duration of exposure, tissues can either absorb the energy (photocoagulation, thermotherapy, and PDT) or undergo ionization (photodisruption). ${ }^{3}$ Ocular phototherapy applications for treatment of ocular tumours are based on principles of absorption of energy. However, the tissue reaction to absorbed energy vary from coagulation or denaturation (photocoagulation), tissue heat (thermotherapy), or release of singlet oxygen (PDT). ${ }^{4}$

\section{Tissue pigments}

The light or radiant energy can be easily applied to ocular surface or delivered to the intraocular structures through pupil across the clear media. For phototherapy to be effective, the energy has
Received: 8 October 2012 Accepted: 11 October 2012 Published online:

14 December 2012
Keywords: phototherapy; tumour 
to be absorbed by tissues or more specifically by naturally occurring pigment within them. Based on distribution and absorption spectrum of the pigment, laser source of a particular wavelength can be selected to achieve tissue-specific damage.

Natural pigments Xanthophyll, which is confined to the macula, has a narrow absorption spectrum confined to blue wavelengths. Haemoglobin mostly absorbs blue, green, and yellow wavelengths. Melanin offers least specificity as it has the broadest absorption spectrum that extends across blue, green, yellow, and red wavelengths (Figure 1). ${ }^{3}$

Injected pigments In tissues or tumours that lack natural pigment such as amelanotic melanoma or choroidal haemangioma, dyes with narrow absorption spectrum can be injected intravenously that act as focal absorbent of laser energy after they have preferentially localized within the tumour. Such targeted phototherapy is the underlying basis of PDT.

Commonly used photosensitizers in treatment of ocular tumours include indocyanine green (to enhance uptake in thermotherapy) and verteporphin (Visudyne).

\section{Photocoagulation}

\section{General principles}

Photocoagulation is the thermal denaturation of tissues. Tumours containing haemoglobin and melanin can readily absorb argon or krypton laser wavelengths and therefore, on theoretical grounds be considered for treatment of ocular tumours. Overall, the role of photocoagulation is limited because of concerns for tumour dissemination, tumour recurrences, and availability of more effective treatments.

\section{Indications and results}

Retinal tumours Small retinoblastoma ( $<3 \mathrm{~mm}$ in base, $<2.0 \mathrm{~mm}$ in height) can be treated with photocoagulation mostly to the surrounding retina in an attempt to cutoff the vascular supply rather than direct photocoagulation because of concerns for dissemination retinoblastoma cells into the overlying vitreous cavity. ${ }^{5}$ With advent of thermotherapy for retinoblastoma, photocoagulation is used very infrequently.

Retinal capillary haemangioma ( $\mathrm{RCH}$; juxtapapillary and extrapapillary variants) have been treated with photocoagulation. ${ }^{6,7}$ Photocoagulation is applied as a combination of direct and feeder vessel occlusion technique. ${ }^{8}$ Overall the control rates vary between 75 and $90 \%$. Photocoagulation is particularly effective in controlling small extrapapillary tumours $(1.5 \mathrm{~mm}$ or smaller; Figure 2). ${ }^{9}$ PDT is being increasingly used for treatment of juxtapapillary retinal haemangioma, because of risk of thermal optic nerve damage. ${ }^{10}$

Choroidal tumours Choroidal melanoma and choroidal haemangioma have been treated in the past with photocoagulation. As a result of concerns for the lack of efficacy (haemangioma) ${ }^{11}$ and recurrences (melanoma) over the long term, ${ }^{12}$ photocoagulation has been abandoned in favour of PDT (haemangioma) and radiation plaque therapy (melanoma).

\section{Thermotherapy}

\section{General principles}

Oosterhuis et al ${ }^{13}$ introduced the concept of transpupillary thermotherapy (TTT) in 1995. During TTT, the tumour is heated to a temperature of $60-65^{\circ} \mathrm{C}$ by means of an infrared diode laser applied via the pupil. The rise in temperature causes cytotoxicity. As original descriptions, several publications have reported use of TTT treatment of retinoblastoma (with or without chemotherapy) and a variety of choroidal tumours (melanoma, haemangioma, and metastases).

\section{Indications and results}

Retinoblastoma TTT is generally used for relatively small tumours without associated vitreous or subretinal seeds and is used in conjunction with adjuvant chemotherapy (Figure 3). In a series of 188 tumours that had mean tumour diameter of $3.0 \mathrm{~mm}$ and thickness of $2.0 \mathrm{~mm}$, tumour regression was achieved in $86 \%$ with a recurrence rate of $14 \%$. Larger tumours are at greater risk for complications such as focal iris atrophy and focal paraxial lens opacity because they require more intense therapy as compared with smaller tumours. ${ }^{14,15}$

Choroidal melanoma Several investigators have used TTT as primary or sole therapy for 'small' choroidal melanocytic lesions (melanomas $<4 \mathrm{~mm}$ in height or high-risk naevi with or without documented growth). ${ }^{9}$ Complications of the TTT such as epiretinal membrane, retinal traction, retinal detachment, vascular occlusions, and absolute wedge-shaped scotoma have been reported. ${ }^{16}$ However, the main concern is of local tumour recurrence. ${ }^{17,18}$ The published local recurrence rates have ranged from 8 to $56 \%$ because of variable inclusion criteria and follow-up times. The pooled data (602 tumours and 100 recurrences), revealed a weighted mean tumour recurrence rate of $17 \%$ with median follow-up of 37 months. Of these, $7 \%$ were extrascleral (Figure 4). ${ }^{19}$ 
Alternative methods of management (other than observation) such as either proton or plaque radiotherapy offer tumour control rates exceeding $90 \% .^{20}$ We consider it advisable to counsel the patient of a possibility of delayed tumour recurrence when proposing TTT as sole therapy for small choroidal melanoma. TTT is also used as adjunct in combination with plaque radiotherapy, particularly for tumours in

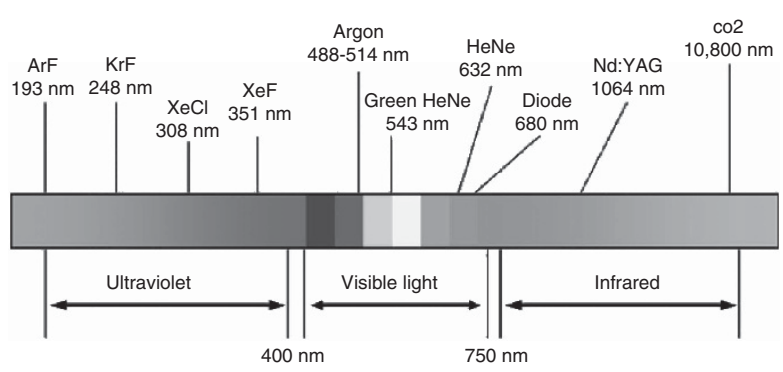

Figure 1 Absorption of visible wavelengths by three ocular pigments (melanin, haemoglobin, and xanthophyll). Modified with permission from Peyman et al. ${ }^{3}$ juxtapapillary location to minimize the risk of juxtapapillary recurrence. ${ }^{21}$

Other choroidal tumours TTT can be a convenient and cost effective treatment option in the management of small choroidal metastatic tumours (thickness $<3.5 \mathrm{~mm}$ ) providing local control. ${ }^{22}$ Similarly, TTT has also been used to treat circumscribed choroidal haemangioma. In a review of published studies, $42 \%$ cases showed complete regression with additional 53\% demonstrating partial regression. ${ }^{23}$ Complications such as cystoid macular oedema, preretinal fibrosis, focal iris atrophy, and retinal vascular occlusion ${ }^{23}$ can be avoided with the use of PDT while achieving equally high response rate.

\section{Photodynamic therapy}

\section{General principles}

Verteporfin (Visudyne; Novartis; Basil, Switzerland) PDT is a non-thermal, photobiochemical procedure that offers
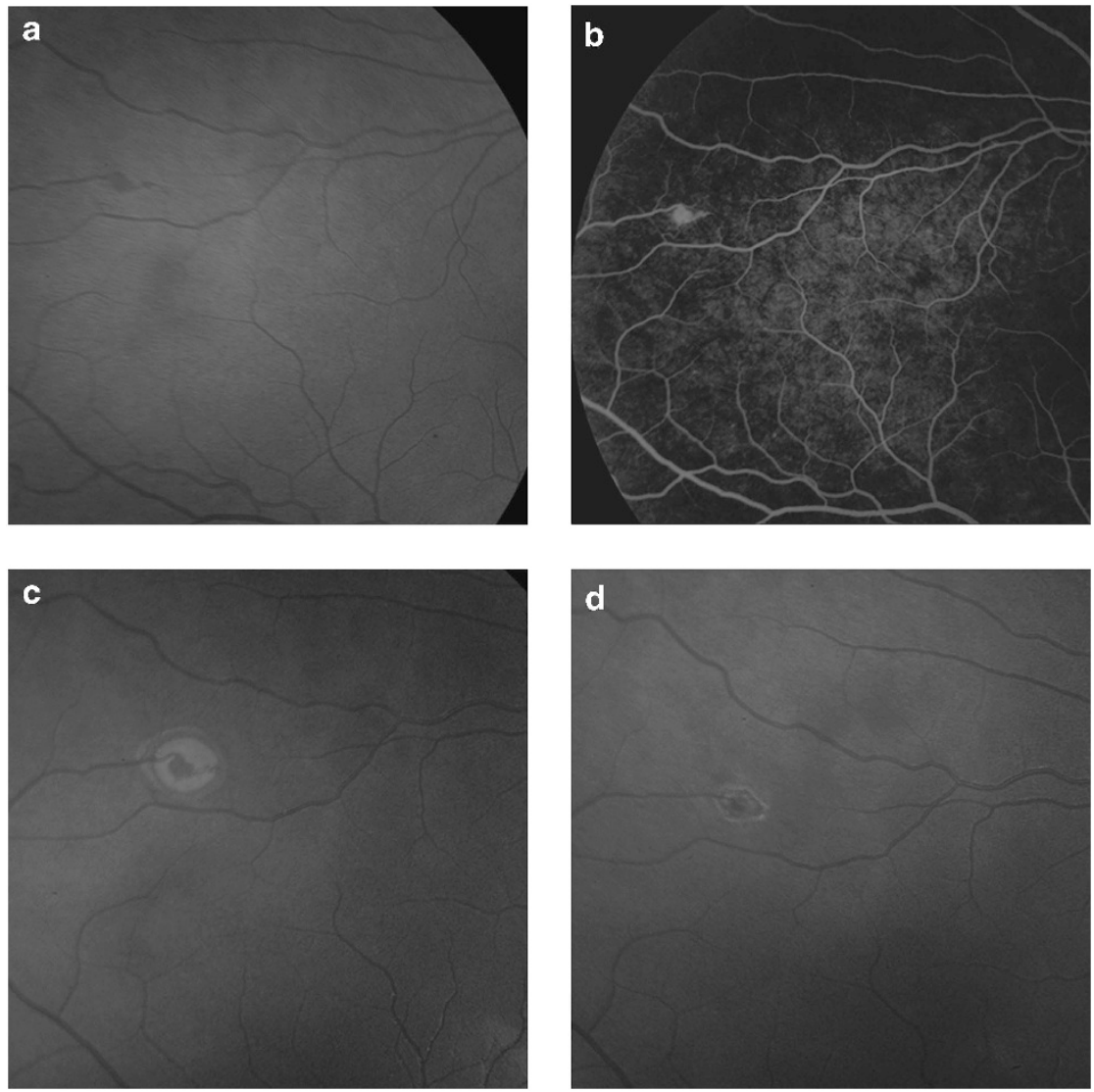

Figure 2 Small RCH observed on surveillance examination in a patient with VHL disease (a). The haemangioma could be visualized with fluorescein angiography (b). Appearance immediately after laser photocoagulation (c). Four weeks later, the haemangioma is partially regressed and surrounded by a chorioretinal scar (d). Reproduced with permission from: Singh AD, Schachat AP. Treatment of retinal capillary hemangioma. In Ophthalmic Surgery: Principles and Practice 4ed. Spaeth GL, Danesh-Meyer HV, Goldberg I, Kampik A (Eds). Elsevier-Saunders: Philadelphia; 2012. pp 622-623. 

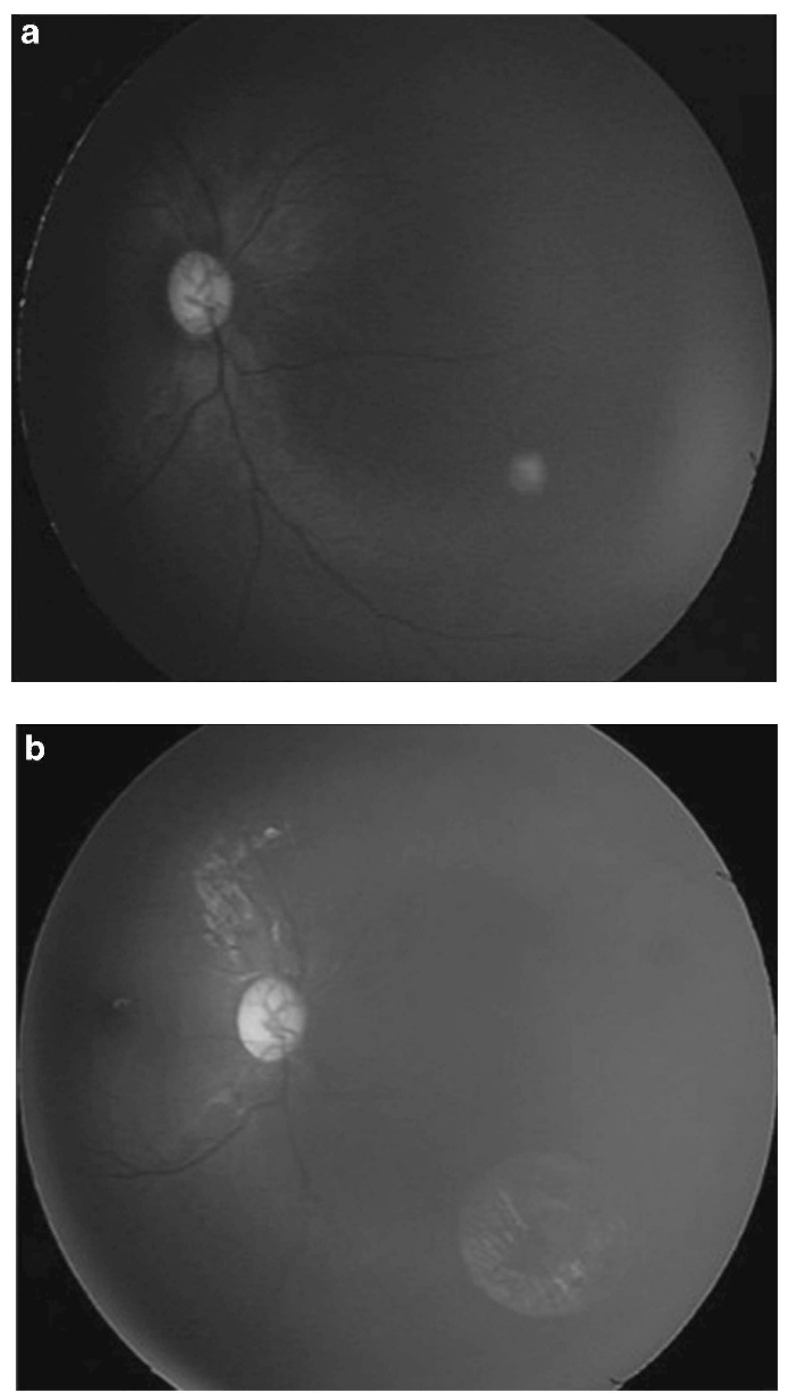

Figure 3 Fundus appearance immediately after thermotherapy of a $1 \mathrm{~mm}$ retinoblastoma (a). Four weeks later, the tumour is replaced by a chorio retinal scar (b).

site-specific vascular occlusion and tumour destruction with minimal damage to adjacent neural structures. ${ }^{24-26}$ The safety of PDT has been established treatment of choroidal neovascularization because of age-related macular degeneration. ${ }^{27}$

\section{Indications and results}

Eyelid tumours PDT is used extensively in the field of dermatology for a variety of inflammatory conditions and premalignant and malignant tumours including basal cell carcinoma (BCC). ${ }^{28}$ PDT has also been used for treatment of periocular BCC in a small number of cases. Preliminary experience suggests promising results without any complications..$^{29,30}$
Conjunctival tumours The preliminary results suggest that PDT may be an alternative treatment for ocular surface squamous neoplasia, particularly with diffuse presentation. ${ }^{31-33}$

Retinal tumours PDT with verteporfin causes fewer side effects as it offers site-specific tumour destruction while sparing surrounding structures. ${ }^{26}$ Moreover, red wavelength has deeper penetration into the haemangioma than laser photocoagulation. ${ }^{34}$ Verteporfin has enhanced selectivity for tissues (including murine vascular tumourigenic cell lines) with upregulated lowdensity lipoprotein receptors. ${ }^{26}$ In addition,

intravenously injected verteporfin pools within the $\mathrm{RCH}$, offering a site-specific target for PDT. ${ }^{26}$ The vascular effects of PDT may include remodelling of the vascular wall with reduced permeability rather than vascular occlusion. ${ }^{26,34}$

Retinal capillary haemangioma: For reasons outlined above, several investigators have reported their preliminary experience of treating $\mathrm{RCH}$ with PDT. ${ }^{26,34-36}$ Both extrapapillary ${ }^{26}$ and juxtapapillary $\mathrm{RCH}^{10,34,35}$ have been treated with varying parameters of laser settings. Except in one case wherein the tumour response to PDT was transient, ${ }^{35}$ the tumours showed sustained response to PDT including reduced perfusion, shrinkage, and resolution of subretinal fluid. ${ }^{10,26,34,36}$ Visual acuity improved or remained stable in the majority of eyes $(67 \%)$.

Visually significant complications such as retinal vascular occlusion, ${ }^{26}$ optic neuropathy, ${ }^{26}$ vitreous haemorrhage, ${ }^{26}$ and tractional retinal detachment ${ }^{10,36}$ are observed infrequently. The treatment parameters are based on settings of the TAP protocol or some modifications of it. Increased fluence $\left(100 \mathrm{~J} / \mathrm{cm}^{2}\right)$ appears to be associated with higher rate of complications especially in the juxtapapillary $\mathrm{RCH} .{ }^{26}$ In our own limited experience, PDT of $\mathrm{RCH}$ with TAP parameters is moderately effective in treatment of $\mathrm{RCH} .{ }^{10}$

Retinal vasoproliferative tumour: As these tumours also have distinct vascular component, PDT can be used to achieve tissue sparing treatment. ${ }^{37}$

Retinal astrocytic hamartoma: Retinal astrocytomas are benign gliocytic tumours occurring sporadically or in association with tuberous sclerosis. In the setting of tuberous sclerosis, the incidence of astrocytic hamartoma of the retina is about $50 \%$, and these lesions are often bilateral and multiple. ${ }^{38}$ Their vascular nature likely underlies at least some of the complications, including retinal serous and lipid exudation. ${ }^{39-41}$ Treatment with PDT in a few cases of exudative astrocytic hamartomas with encouraging results has been reported. ${ }^{42-44}$ 

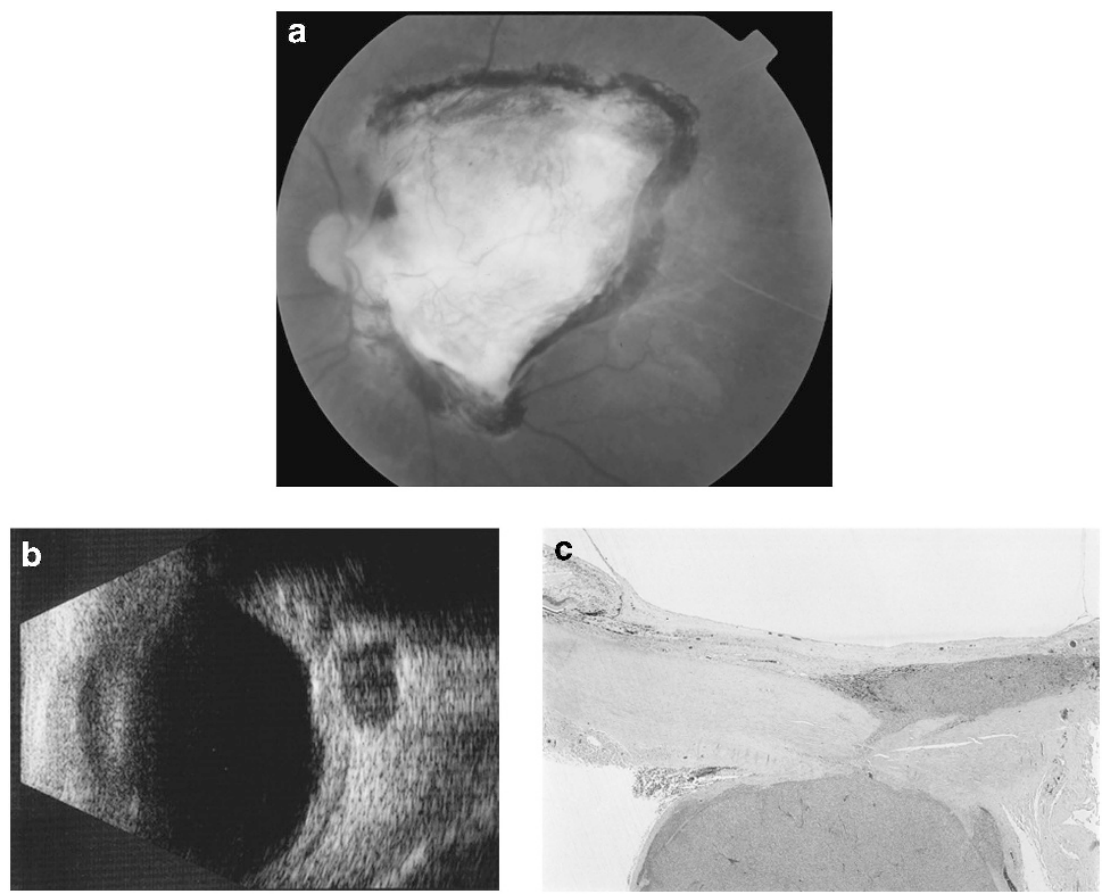

Figure 4 External recurrence following TTT. Fundus photograph showing fibrotic membrane with fine retinal neovascularization at the treated site of small choroidal melanoma following three sessions of TTT (a). B-scan ultrasonograph demonstrated a nodular extrascleral extension along the base of the original tumour (b). Photomicrograph of the posterior pole of the eye with an extensive chorioretinal scar at the site of thermotherapy. Residual deep choroidal tumour extends via a scleral canal to the extrascleral tumour nodule (c). Reproduced with permission from Singh et al. ${ }^{18}$

Circumscribed choroidal haemangioma Various treatment modalities including argon laser photocoagulation, cryotherapy, external beam radiotherapy, proton beam radiotherapy, episcleral plaque radiotherapy, and TTT have been tried with varying degrees of success in stabilizing or improving visual acuity. ${ }^{45}$ The major limitation of these treatment modalities is the risk of damage to the overlying retina. As indicated above, PDT offers the advantage of tissue-specific treatment.

Overall, excellent anatomical and functional results have been reported (Figure 5). ${ }^{45}$ The treatment technique has varied between investigators with some following TAP protocol ${ }^{46-48}$ and others favouring a bolus injection to compensate for altered haemodynamics within the choroidal haemangioma. ${ }^{49-52}$ We have preferred to use the standard TAP study protocol rather than a bolus injection because of greater experience with TAP study protocol and equally good results obtained in patients treated with either protocol. ${ }^{45}$

\section{Diffuse choroidal haemangioma}

Tumour regression and resolution of subretinal fluid in the setting of diffuse choroidal haemangioma (Sturge-
Weber Syndrome) is generally treated with low-dose radiotherapy or proton beam radiotherapy. ${ }^{53}$ Review of six published cases, suggests that PDT can also be effective. ${ }^{54}$ However, there is a concern for exudative hyper response following PDT (Figure 6). ${ }^{55}$

\section{Choroidal melanoma}

Although experimental studies have demonstrated evidence of melanoma regression following PDT 56 attempts at treatment of choroidal melanoma with PDT in the clinical setting have been disappointing. 57,58

\section{Choroidal metastases}

Limited clinical experience suggests that PDT is effective in treatment of symptomatic choroidal metastases that have failed chemotherapy. ${ }^{59}$

\section{Conclusions}

Ocular phototherapy has broad applications in treatment of ocular tumours. Laser photocoagulation, thermotherapy, and PDT can be delivered with low rates of complications and with ease in the outpatient setting. 
Review of the current literature suggests excellent results when these treatments are applied for benign tumours, particularly for vascular tumours such as circumscribed choroidal haemangioma. For primary malignant tumours, such as choroidal melanoma, thermotherapy, and PDT do not offer local tumour control rates that are
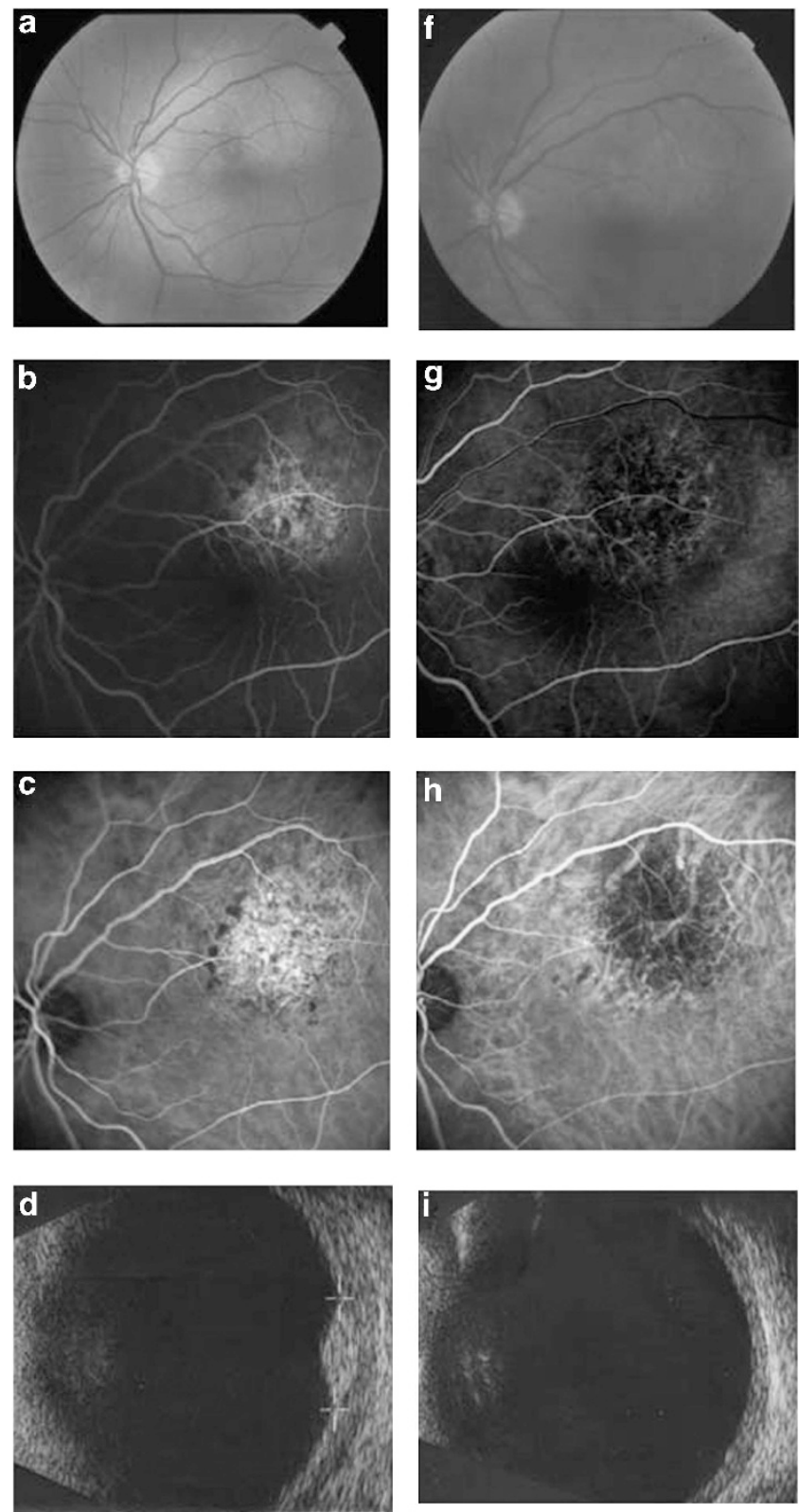

e

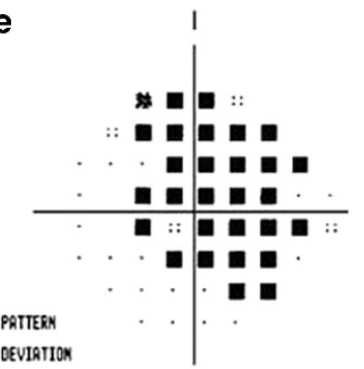

j

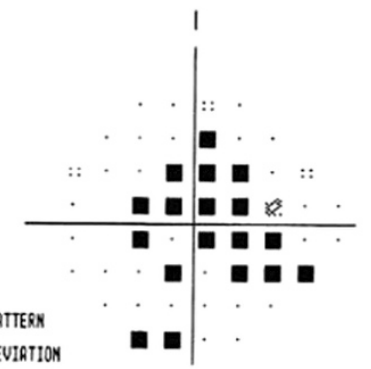


equivalent or higher than those achieved with plaque or proton radiation therapy. However, for secondary malignant tumours (choroidal metastases), thermotherapy and PDT can be applied as a palliative treatment. Greater experience is necessary to fully comprehend risks, comparative benefits, and complication of ocular phototherapy of ocular tumours.
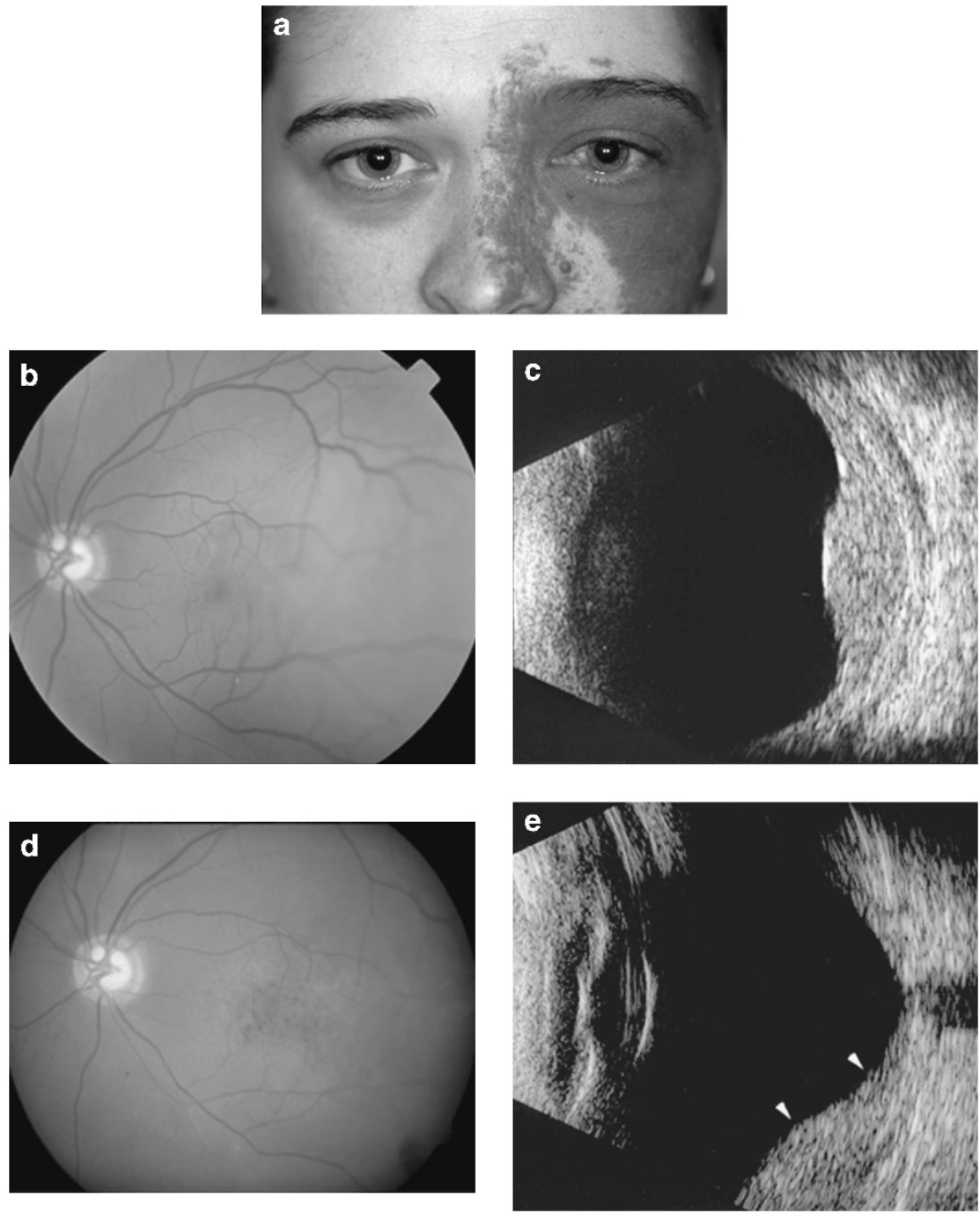

Figure 6 External photograph showing haemangioma distribution typical of Sturge-Weber syndrome (a). Fundus photograph showing diffuse choroidal thickening with a more prominent localized thickening in the temporal quadrant (b). B-scan ultrasonography (c). Note the dome-shaped choroidal mass that blends with the diffusely thickened choroid. Fundus photograph showing prominence of retinal pigmentation at the treatment site (d) with corresponding flattening of the choroidal haemangioma on B-scan ultrasonography (e). Note the flattening of the posterior aspect of choroidal haemangioma (between arrow heads). Reproduced with permission from Singh et al. ${ }^{55}$

Figure 5 Fundus photograph of the left eye showing an amelanotic juxtafoveal circumscribed choroidal haemangioma (a). Fluorescein angiogram (b, arterio-venous phase). Note circumscribed hyperfluorescence corresponding to the location of the choroidal haemangioma. Indocyanine green angiogram showing hypervascularity and hyperfluorescence because of choroidal haemangioma (c). B-scan ultrasonograph of a dome-shaped choroidal lesion and high internal reflectivity (thickness $2.5 \mathrm{~mm}$ ) (d). Central visual field defects documented before PDT (e). Post-treatment fundus appearance showing regression of haemangioma (f). Post-treatment fluorescein angiogram showing absence of pre-treatment hyperfluorescence $(\mathrm{g})$. Post-treatment indocyanine green angiogram demonstrating that the choroidal haemangioma is replaced by an area of hypovascular choroid (h). Post-treatment B-scan ultrasonograph showing complete flattening of the choroidal haemangioma (i). Post-treatment central visual field. Note lack of progression of pre-treatment field defects (j). Reproduced with permission from Gupta et al. ${ }^{60}$ 


\section{Conflict of interest}

The author declares no conflict of interest.

\section{References}

1 L'Esperance FJ. Ophthalmic Lasers. CV Mosby: St Louis, 1983.

2 Fankhauser F, Kwasniewska S. Laser in Ophthalmology. Basic, Diagnostic and Surgical Aspects. Kugler Publications: The Hague, 2003.

3 Peyman GA, Raichand M, Zeimer RC. Ocular effects of various laser wavelengths. Surv Ophthalmol 1984; 28(5): 391-404.

4 Sacu S, Schmidt-Erfurth U. Principles of laser therapy. In: Singh AD, Damato BE, Pe'er J, Murphree AL, Perry JD (eds) Clinical Ophthalmic Oncology. Saunders-Elsevier: Philadelphia, 2007, pp 37-39.

5 Shields CL, Shields JA, Kiratli H, De Potter PV. Treatment of retinoblastoma with indirect ophthalmoscope laser photocoagulation. J Pediatr Ophthalmol Strabismus 1995; 32(5): 317-322.

6 Lane CM, Turner G, Gregor ZJ, Bird AC. Laser treatment of retinal angiomatosis. Eye (Lond) 1989; 3(Part 1): 33-38.

7 Schmidt D, Natt E, Neumann HP. Long-term results of laser treatment for retinal angiomatosis in von Hippel-Lindau disease. Eur J Med Res 2000; 5(2): 47-58.

8 Blodi CF, Russell SR, Pulido JS, Folk JC. Direct and feeder vessel photocoagulation of retinal angiomas with dye yellow laser. Ophthalmology 1990; 97(6): 791-795; discussion 796-797.

9 Shields CL, Shields JA, Perez N, Singh AD, Cater J. Primary transpupillary thermotherapy for small choroidal melanoma in 256 consecutive cases: outcomes and limitations. Ophthalmology 2002; 109(2): 225-234.

10 Sachdeva R, Dadgostar H, Kaiser PK, Sears JE, Singh AD. Verteporfin photodynamic therapy of six eyes with retinal capillary haemangioma. Acta Ophthalmol 2010; 88(8): e334-340.

11 Shields CL, Honavar SG, Shields JA, Cater J, Demirci H. Circumscribed choroidal hemangioma: clinical manifestations and factors predictive of visual outcome in 200 consecutive cases. Ophthalmology 2001; 108(12): 2237-2248.

12 Brancato R, Menchini U, Pece A. Enucleation after argon laser photocoagulation for choroidal melanoma. Ann Ophthalmol 1988; 20(8): 296-298.

13 Oosterhuis JA, Journee-de Korver HG, Kakebeeke-Kemme HM, Bleeker JC. Transpupillary thermotherapy in choroidal melanomas. Arch Ophthalmol 1995; 113(3): 315-321.

14 Shields CL, Santos MC, Diniz W, Gunduz K, Mercado G, Cater JR et al. Thermotherapy for retinoblastoma. Arch Ophthalmol 1999; 117(7): 885-893.

15 Abramson DH, Schefler AC. Transpupillary thermotherapy as initial treatment for small intraocular retinoblastoma: technique and predictors of success. Ophthalmology 2004; 111(5): 984-991.

16 Currie ZI, Rennie IG, Talbot JF. Retinal vascular changes associated with transpupillary thermotherapy for choroidal melanomas. Retina 2000; 20(6): 620-626.

17 Zaldivar RA, Aaberg TM, Sternberg Jr., P, Waldron R, Grossniklaus HE. Clinicopathologic findings in choroidal melanomas after failed transpupillary thermotherapy. Am J Ophthalmol 2003; 135(5): 657-663.
18 Singh AD, Rundle PA, Berry-Brincat A, Parsons MA, Rennie IG. Extrascleral extension of choroidal malignant melanoma following transpupillary thermotherapy. Eye (Lond) 2004; 18(1): 91-93.

19 Singh AD, Kivela T, Seregard S, Robertson D, Bena JF. Primary transpupillary thermotherapy of "small" choroidal melanoma: is it safe? Br J Ophthalmol 2008; 92(6): 727-728

20 Seregard S, Damato B, Fleming P. Uveal malignant melanoma: management options - brachytherapy. In: Singh AD, Damato BE, Pe'er J, Murphree AL, Perry JD (eds) Clinical Ophthalmic Oncology. Elsevier-Saunder: Philadelphia, 2007, pp 241-247.

21 Sagoo MS, Shields CL, Mashayekhi A, Freire J, Emrich J, Reiff J et al. Plaque radiotherapy for juxtapapillary choroidal melanoma: tumor control in 650 consecutive cases. Ophthalmology 2011; 118(2): 402-407.

22 Kiratli H, Bilgic S. Transpupillary thermotherapy in the management of choroidal metastases. Eur J Ophthalmol 2004; 14(5): 423-429.

23 Gunduz K. Transpupillary thermotherapy in the management of circumscribed choroidal hemangioma. Surv Ophthalmol 2004; 49(3): 316-327.

24 Schmidt-Erfurth U, Hasan T, Gragoudas E, Michaud N, Flotte TJ, Birngruber R. Vascular targeting in photodynamic occlusion of subretinal vessels. Ophthalmology 1994; 101(12): 1953-1961.

25 Schmidt-Erfurth U, Hasan T, Schomacker K, Flotte T, Birngruber R. In vivo uptake of liposomal benzoporphyrin derivative and photothrombosis in experimental corneal neovascularization. Lasers Surg Med 1995; 17(2): 178-188.

26 Schmidt-Erfurth UM, Kusserow C, Barbazetto IA, Laqua H. Benefits and complications of photodynamic therapy of papillary capillary hemangiomas. Ophthalmology 2002; 109(7): 1256-1266.

27 Group Toa-rmdwptTS.. Photodynamic therapy of subfoveal choroidal neovascularization in age-related macular degeneration with verteporfin: one-year results of 2 randomized clinical trials-TAP report. Treatment of age-related macular degeneration with photodynamic therapy (TAP) Study Group. Arch Ophthalmol 1999; 117(10): 1329-1345.

28 Lee Y, Baron ED. Photodynamic therapy: current evidence and applications in dermatology. Semin Cutan Med Surg 2011; 30(4): 199-209.

29 Kotimaki J. Photodynamic therapy of eyelid basal cell carcinoma. J Eur Acad Dermatol Venereol 2009; 23(9): 1083-1087.

30 Puccioni M, Santoro N, Giansanti F, Ucci F, Rossi R, Lotti T et al. Photodynamic therapy using methyl aminolevulinate acid in eyelid basal cell carcinoma: a 5-year follow-up study. Ophthal Plast Reconstr Surg 2009; 25(2): 115-118.

31 Hirst LW. Treatment of conjunctival squamous cell carcinoma with photodynamic therapy. Am J Ophthalmol 2005; 139(4): 759-760; author reply 760 .

32 Barbazetto IA, Lee TC, Abramson DH. Treatment of conjunctival squamous cell carcinoma with photodynamic therapy. Am J Ophthalmol 2004; 138(2): 183-189.

33 Sears KS, Rundle PR, Mudhar HS, Rennie IG. The effects of photodynamic therapy on conjunctival in situ squamous cell carcinoma-a review of the histopathology. $\mathrm{Br} \mathrm{J}$ Ophthalmol 2008; 92(5): 716-717.

34 Atebara NH. Retinal capillary hemangioma treated with verteporfin photodynamic therapy. Am J Ophthalmol 2002; 134(5): 788-790. 
35 Bakri SJ, Sears JE, Singh AD. Transient closure of a retinal capillary hemangioma with verteporfin photodynamic therapy. Retina 2005; 25(8): 1103-1104.

36 Aaberg Jr TM, Aaberg Sr TM, Martin DF, Gilman JP, Myles $\mathrm{R}$. Three cases of large retinal capillary hemangiomas treated with verteporfin and photodynamic therapy. Arch Ophthalmol 2005; 123(3): 328-332.

37 Barbezetto IA, Smith RT. Vasoproliferative tumor of the retima treated with PDT. Retina 2003; 23(4): 565-567.

38 Aronow ME, Nakagawa JA, Gupta A, Traboulsi EI, Singh AD. Tuberous sclerosis complex: genotype/phenotype correlation of retinal findings. Ophthalmology 2012; 119(9): 1917-1923.

39 Atkinson A, Sanders MD, Wong V. Vitreous haemorrhage in tuberous sclerosis. Report of two cases. Br J Ophthalmol 1973; 57(10): 773-779.

40 Vrabec TR, Augsburger JJ. Exudative retinal detachment due to small noncalcified retinal astrocytic hamartoma. Am J Ophthalmol 2003; 136(5): 952-954.

41 Giles J, Singh AD, Rundle PA, Noe KP, Rennie IG. Retinal astrocytic hamartoma with exudation. Eye (Lond) 2005; 19(6): 724-725

42 Eskelin S, Tommila P, Palosaari T, Kivela T. Photodynamic therapy with verteporfin to induce regression of aggressive retinal astrocytomas. Acta Ophthalmol 2008; 86(7): 794-799.

43 Mennel S, Hausmann N, Meyer CH, Peter S. Photodynamic therapy for exudative hamartoma in tuberous sclerosis. Arch Ophthalmol 2006; 124(4): 597-599.

44 Shields CL, Materin MA, Marr BP, Krepostman J, Shields JA. Resolution of exudative retinal detachment from retinal astrocytoma following photodynamic therapy. Arch Ophthalmol 2008; 126(2): 273-274.

45 Singh AD, Kaiser PK, Sears JE, Gupta M, Rundle PA, Rennie IG. Photodynamic therapy of circumscribed choroidal haemangioma. Br J Ophthalmol 2004; 88(11): 1414-1418.

46 Madreperla SA. Choroidal hemangioma treated with photodynamic therapy using verteporfin. Arch Ophthalmol 2001; 119(11): 1606-1610.

47 Landau IM, Steen B, Seregard S. Photodynamic therapy for circumscribed choroidal haemangioma. Acta Ophthalmol Scand 2002; 80(5): 531-536.

48 Porrini G, Giovannini A, Amato G, Ioni A, Pantanetti M. Photodynamic therapy of circumscribed choroidal hemangioma. Ophthalmology 2003; 110(4): 674-680.
49 Barbazetto I, Schmidt-Erfurth U. Photodynamic therapy of choroidal hemangioma: two case reports. Graefes Arch Clin Exp Ophthalmol 2000; 238(3): 214-221.

50 Jurklies B, Anastassiou G, Ortmans S, Schuler A, Schilling $\mathrm{H}$, Schmidt-Erfurth $\mathrm{U}$ et al. Photodynamic therapy using verteporfin in circumscribed choroidal haemangioma. $\mathrm{Br} \mathrm{J}$ Ophthalmol 2003; 87(1): 84-89.

51 Schmidt-Erfurth UM, Michels S, Kusserow C, Jurklies B, Augustin AJ. Photodynamic therapy for symptomatic choroidal hemangioma: visual and anatomic results. Ophthalmology 2002; 109(12): 2284-2294.

52 Verbraak FD, Schlingemann RO, Keunen JE, De Smet MD. Longstanding symptomatic choroidal hemangioma managed with limited PDT as initial or salvage therapy. Graefes Arch Clin Exp Ophthalmol 2003; 241(11): 891-8.

53 Zografos L, Egger E, Bercher L, Chamot L, Munkel G. Proton beam irradiation of choroidal hemangiomas. Am J Ophthalmol 1998; 126(2): 261-268.

54 Tsipursky MS, Golchet PR, Jampol LM. Photodynamic therapy of choroidal hemangioma in sturge-weber syndrome, with a review of treatments for diffuse and circumscribed choroidal hemangiomas. Surv Ophthalmol 2011; 56(1): 68-85.

55 Singh AD, Rundle PA, Vardy SJ, Rennie IG. Photodynamic therapy of choroidal haemangioma associated with SturgeWeber syndrome. Eye (Lond) 2005; 19(3): 365-367.

56 Schmidt-Erfurth U, Bauman W, Gragoudas E, Flotte TJ, Michaud NA, Birngruber R et al. Photodynamic therapy of experimental choroidal melanoma using lipoproteindelivered benzoporphyrin. Ophthalmology 1994; 101(1): 89-99.

57 Barbazetto IA, Lee TC, Rollins IS, Chang S, Abramson DH. Treatment of choroidal melanoma using photodynamic therapy. Am J Ophthalmol 2003; 135(6): 898-899.

58 Canal-Fontcuberta I, Salomao DR, Robertson D, Cantrill HL, Koozekanani D, Rath PP et al. Clinical and histopathologic findings after photodynamic therapy of choroidal melanoma. Retina 2012; 32(5): 942-948.

59 Kaliki S, Shields CL, Al-Dahmash SA, Mashayekhi A, Shields JA. Photodynamic therapy for choroidal metastasis in 8 cases. Ophthalmology 2012; 119(6): 1218-1222.

60 Gupta M, Singh AD, Rundle PA, Rennie IG. Efficacy of photodynamic therapy in circumscribed choroidal haemangioma. Eye (Lond) 2004; 18(2): 139-142. 